\title{
Avaliação e internacionalização da Educação Superior: Quo vadis América Latina?
}

\author{
DeNISE LEITE* \\ Maria Elly Herz Genro** \\ Recebido: 03 jul. 2012 \\ Aprovado: 25 jul. 2012
}

\begin{abstract}
*Doutora em Ciências Humanas pela Universidade Federal do Rio Grande do Sul. Professora Titular aposentada, docente permanente convidada do Programa de Pós-Graduação em Educação da UFRGS, e pesquisadora Nível 1B, CNPq (Conselho Nacional de Pesquisa). Porto Alegre, RS, Brasil. E-mail: denise.leite@pq.cnpq.br **Mestre e Doutora em Educação. Professora da UFRGS, vinculada ao Grupo de Pesquisa Inovação e Avaliação no PPGEdu/UFRGS. Atua nos seguintes temas: Universidade, Avaliação institucional, Inovação, Cidadania e Ensino Superior. Porto Alegre, RS, Brasil. E-mail: mariaellyh8@gmail.com
\end{abstract}

Resumo: Este artigo apresenta os temas da avaliação, acreditação e internacionalização das instituições de educação superior de América Latina e Caribe. Discute os cânones da globalização e da mercadorização da educação superior, contextos nos quais se estabelecem as políticas de avaliação. Apresenta as imbricações entre os conceitos de hegemonia, imperialismo e globalização neoliberal que sustentam sua compreensão. A seguir, levanta evidências sobre a constituição e 'práticas' de um novo imperialismo, o imperialismo benevolente, que está a produzir as estratégias do Processo de Bolonha com vistas à formação de uma zona comum de educação superior formada por América Latina, Caribe e União Europeia. Há atores hegemônicos que sustentam estes interesses. Demonstra a seguir, a existência de suas ações na indução de relações entre agências de acreditação e avaliação, entre redes de agências, entre projetos para o estabelecimento de indicadores institucionais globais que redundam em procedimentos para internacionalização das instituições de educação superior. Ao final, argumenta que as políticas têm consequências sobre os caminhos futuros da educação superior latino-americana porque geram novos modelos de instituições e induzem à formação de valores que negam o fortalecimento do espaço público e a reinvenção de subjetividades democráticas.

Palavras-chave: Políticas avaliação. Internacionalização; Redes Acreditação. Imperialismo benevolente. Educação Superior.

\section{EVALUATION AND INTERNATIONALIZATION OF HIGHER EDUCATION. QUO VADIS LATIN AMERICA?}

Abstract: This paper discuss the themes of evaluation, accreditation and internationalization of higher education institutions of Latin America and Caribbean. The canons of globalization and commodification of higher education, contexts in which are established policies for evaluation, are discussed. The relations between the concepts of hegemony, imperialism and neoliberal globalization that sustain their understanding are also presented. Next, raises evidence of a " practice ' of a new imperialism, benevolent imperialism, that is producing the strategies of the Bologna process with a view to the formation of a common area of higher education formed by Latin America, Caribbean and European Union. There are actors that sustain these hegemonic interests. The existence of their actions in the induction of inter-agency relations, accreditation and evaluation agency networks, between projects for the establishment of global institutional indicators that implies procedures for internationalization of higher education institutions are showed. In the end, it argues that policies have consequences on the higher education future in Latin America and Caribbean because they generate new types of institutions and induce the formation of values that can deny the public space and the reinvention of democratic subjectivities.

Key words: Evaluation Policies. Internationalization. Accreditation Networks. Benevolent imperialism. Higher Education. 


\title{
EVALUACIÓN E INTERNACIONALIZACIÓN DE LA EDUCACIÓN SUPERIOR. ¿QUO VADIS AMÉRICA LATINA?
}

\begin{abstract}
Resumen: Este artículo presenta los temas de evaluación, acreditación e internacionalización de las instituciones de educación superior de América Latina y el Caribe. Discute los cánones de la globalización y la mercantilización de la educación superior, contextos en los cuales se establecen políticas de evaluación. Presenta las imbricaciones entre los conceptos de hegemonía, imperialismo y globalización neoliberal que sustentan su comprensión. A continuación, indica elementos de la 'práctica' de un nuevo imperialismo, imperialismo benevolente, que está produciendo las estrategias del proceso de Bolonia con miras a la formación de un espacio común de educación superior formado por América Latina, el Caribe y la Unión Europea. Hay actores que sustentan a estos intereses hegemónicos. Se demuestra la existencia de sus acciones en la inducción de relaciones entre agencias y redes interinstitucionales de acreditación y evaluación, con proyectos para el establecimiento de indicadores de evaluación globales lo que implica en procedimientos para la internacionalización de las instituciones de educación superior. Al final, argumenta que las políticas tienen consecuencias sobre los caminos futuros de la educación superior en América Latina y Caribe porque generan nuevos tipos de instituciones e inducen a una formación de valores que niegan el fortalecimiento del espacio público y la reinvención de subjetividades democráticas.
\end{abstract}

Palabras clave: Políticas de evaluación; Internacionalización; Redes de acreditación; Imperialismo benevolente; Educación Superior

\section{INTRODUÇÃO}

Uma nova epistemologia da Educação Superior surge no século 21. Esta epistemologia sustenta as razões pelas quais as universidades devem trilhar caminhos globais e internacionais, redesenhar seu perfil em direção aos mercados e desenvolver modalidades de capitalismo acadêmico. Contribuíram para formar e dar sentido a esta episteme o movimento das reformas dos sistemas de Educação Superior (SES) latino-americanos, as chamadas reformas dos anos 90.

No bojo da modernização do estado, as reformas tiveram consequências semelhantes nos diferentes países da América Latina (AL): expansão do sistema educativo privado; ampliação do acesso e das matrículas com oferta maior na rede privada; cobrança de taxas de matrícula; diferenciação salarial entre os acadêmicos; introdução de sistema merit pay; realocação de recursos públicos; alteração dos percentuais orçamentários de cada país para os diferentes níveis de ensino com menor percentual para a Educação Superior; submissão de políticas públicas às recomendações de órgãos financeiros internacionais.

A epistemologia se fez entender e reconhecer mediante uma neolíngua que acompanhou as reformas neoliberais. Em acordo com a mídia e a retórica global a neolíngua acentuou os termos qualidade, avaliação e credenciamento das instituições de Educação Superior como um fato natural, normal e indispensável ao bom funcionamento dos sistemas. No século 21, a epistemologia, através de sua neolíngua, passou a marcar a urgência das acreditações e da internacionalização das instituições de Educação Superior. 
Ao se entender, reconhecer e aceitar a existência de tal epistemologia no tempo presente, corre-se o risco de também aceitar a despercebida e implícita presença de um novo imperialismo no âmbito dos sistemas de Educação Superior focado no conhecimento e na informação. Neste artigo, uma compilação do Ensaio intitulado Quo vadis? Avaliação e internacionalização da Educação Superior na América Latina ${ }^{1}$, as autoras abordam os assuntos da avaliação, acreditação e internacionalização das instituições de Educação Superior da América Latina e do Caribe. Apresentam hipóteses sobre a existência do novo imperialismo e evidências dessa existência. Argumentam que os processos de avaliação e acreditação internacionais têm o respaldo de uma poderosa e nem sempre visível rede de agências e atores do capitalismo global. Também indicam que tais processos podem ser portadores de consequências ainda não suficientemente reveladas para as instituições de Educação Superior e, por tal motivo, fazem a pergunta que sustenta seu título.

$\mathrm{O}$ tema é fruto de reflexões e estudos das autoras com apoio em pesquisas, referências selecionadas e discussões em diferentes grupos e movimentos dos quais participam ou participaram.

\section{GLOBALIZAÇÃO, MERCADORIZAÇÃO DA EDUCAÇÃO E O PAPEL DA AVALIAÇÃO DA EDUCAÇÃO SUPERIOR}

As avaliações das instituições, cursos e programas que se implantaram a partir das reformas dos anos 1990 se fazem presentes no hoje das instituições de Educação Superior (IES) da América Latina e Caribe. Tais reformas mudaram o cenário da Educação Superior, e surgiram sob a inspiração dos princípios do liberalismo, em sua vertente utilitarista. Esses princípios em regime de democracia representativa de cunho liberal orientariam as escolhas dos cidadãos. Seriam argumentos empregados para justificar a avaliação, credenciamento, classificação, rankings e tipologias de instituições universitárias. A lógica referendava a criação de uma nova necessidade. A necessidade de escolha das instituições que melhor servissem aos propósitos de cada cidadão e de sua família. Esta escolha seria possibilitada pelos resultados de avaliação das IES tornados públicos pelas agências avaliadoras e pelos governos e seus ministérios de educação. Nesse contexto, tais reformas, em verdade, colocaram as IES na rota dos processos de globalização neoliberal.

1 LEITE, Denise Balarine Cavalheiro; GENRO, Maria Elly Herz. Quo vadis? Avaliação e internacionalização da Educação Superior na América Latina. Buenos Aires: CLACSO, 2011. O ensaio completo mereceu o $1^{\circ}$ lugar no concurso CLACSO e recebeu o Premio Pedro Krotsch de Estudios sobre la Universidad: Políticas y Perspectivas sobre la Evaluación Universitaria en América Latina y Caribe em 2011. As autoras agradecem a permissão de CLACSO para a publicação desta versão. 
Nas sociedades latino-americanas, sociedades em desenvolvimento ou periféricas em relação aos centros de poder hegemônico, a importação de modelos de avaliação institucional de lógica neoliberal, com sua neolíngua adjunta, veio a reforçar valores que deslegitimaram práticas locais cuja matriz era originária de vertentes políticas e técnicas embasadas em princípios de democracia igualitária. Nomeia-se, a propósito, a vertente de avaliação participativa tão cara aos latino-americanos (LEITE, 2010).

A forma capitalista neoliberal constitui o protótipo de uma globalização hegemônica. Santos e Avritzer (2002, p. 43) empregam hegemonia no sentido gramsciano, entendida "como capacidade econômica, política, moral e intelectual de estabelecer uma direção dominante na forma de abordagem de uma determinada questão". Os processos de globalização resultariam das interações entre várias constelações de práticas. Mas, uma só globalização seria realmente hegemônica - a capitalista neoliberal.

O dinamismo da globalização foi fortalecido pela existência de um discurso político e ideológico relativamente homogêneo, assentado nos princípios do neoliberalismo, o qual consagrou a aparente solidez e a inevitabilidade do processo em curso como o 'limite da história'. Na ordem econômica internacional a grande corporação transnacional passou a ter lugar de destaque como agente propulsora da economia e dos princípios hegemônicos. Na dinâmica econômica internacional, cresceu a distância entre pobres e ricos no mundo e no interior de cada país. No contexto da globalização hegemônica se produziu um discurso e uma ação de forte homogeneidade, em que o princípio do mercado se sobrepôs ao do Estado; a financeirização da economia sobrepôs os interesses do capital aos interesses do trabalho; o protagonismo das empresas multinacionais foi o agente regulador de uma política que submeteu diferentes esferas da ação humana aos interesses da economia global. A lógica mercantil acirrou a mercadorização da educação (SANTOS, 2001; SANTOS; AVRITZER, 2002).

O processo se produziu com o concurso da ação política dos atores globais privados e das agências financeiras internacionais. Nos diferentes contextos da América Latina (AL), as reformas educacionais, nas quais se insertaram os processos de avaliação das IES, incidiram fortemente sobre o pensamento e a ação educacionais, privilegiaram a preparação profissional em detrimento da formação cidadã e instituíram um modo de redesenho capitalista das universidades em que as lógicas da mercadorização estão presentes.

É importante sinalizar que esse processo não ocorreu sem contradições, sem fissuras, sem resistências. Estas se fizeram presentes através de diferentes experiências de sujeitos coletivos que apontaram para a desmercadorização 
do mundo, um 'outro mundo possível' cujos caminhos seriam tecidos pela democracia participativa no combate a todas as formas de totalitarismos e opressões. As IES latino-americanas, os movimentos sociais, os fóruns, as associações, trouxeram o testemunho sobre outros caminhos possíveis para a democracia igualitária.

O conceito central de hegemonia na perspectiva gramsciana foi entendido como a capacidade de direção intelectual e moral da classe dominante para obter o consenso (passividade) da maioria da população, tendo em vista a consecução de seus interesses e objetivos. Essa tessitura englobaria os intelectuais como organizadores da cultura, tanto os intelectuais tradicionais quanto os orgânicos. A hegemonia orientaria a pauta de discussão intelectual, fundindo os valores dos interesses da classe dominante com os valores de toda a sociedade através da luta hegemônica. O conceito tradicional de hegemonia incluiria as batalhas travadas no âmbito da sociedade civil. A guerra de posições seria parte dessa luta em que se visava à conquista de status e de espaços, de direção político-ideológica para obtenção de consensos entre os setores majoritários da população. Esta seria uma condição para acesso ao poder de Estado com vistas à sua posterior conservação (BOTTOMORE, 1988; COUTINHO, 1996).

$\mathrm{Na}$ tentativa de ampliar e não cristalizar o conceito de hegemonia, em um contexto de complexidade do sistema capitalista atual, neste texto se expressa desconfiança sobre a existência a priori de uma classe social portadora do melhor da humanidade, a chamada classe hegemônica. Acredita-se, isto sim, na emergência de uma diversidade de lutas de sujeitos coletivos, em diferentes tempos, territórios e espaços. As bases que sustentam essas lutas colocam no presente e no horizonte a democracia participativa, o avesso ao individualismo possessivo, a construção de subjetividades sensíveis à dor, ao sofrimento humano, numa insistência existencial de oposição à indiferença social. Por outro lado, reconhece-se que no contexto vivencial onde predomina a indiferença social, está presente o desinvestimento em valores. Nas instituições, especialmente as universidades, observa-se uma tênue preocupação com a reinvenção de valores de finalidades amplas que apontem para a reconstrução da sociedade e contribuam para a busca de sentidos nas diferentes práticas sociais. A sociedade de consumo, a cultura de massas e a transformação da informação e da comunicação parecem tornar superficiais e banalizadas tanto as condições de sobrevivência quanto os modos de pensar os problemas fundamentais da existência humana.

Sob essa ótica, do desinvestimento das instituições, De Alba, em 1994, se reportava a uma dívida intelectual que teria com Pedro Krotsch em relação ao 
seu conceito de 'horizontes utópicos' e a universidade no 'entramado social' do projeto mais amplo da humanidade. De Alba se referia à crise (crise percebida por Krotsch duas décadas antes) que o Estado Avaliador estava a produzir nas universidades levando à carência de horizontes utópicos:

En el momento actual los proyectos sociales se encuentran en crisis y nos encontramos ante la ausencia de horizontes utópicos sociales deseables y viables y presionados por el Estado evaluador (DE ALBA, 1994, p. 18).

Uma grande parte da sociedade, talvez alijada dos mecanismos efetivos de compreensão e decisão política, reforçou o poder da tecnocracia, gerenciadora do funcionamento das instituições sociais na esteira da globalização hegemônica.

Para Lipovetsky (1983, p. 35), a respeito, os especialistas estariam fortalecendo esta lógica,

[...] o sistema funciona, as instituições reproduzem-se e desenvolvem-se, mas em roda livre, sem adesão nem sentido, cada vez mais controladas pelos 'especialistas', os últimos sacerdotes, como diria Nietzsche, os únicos que querem ainda injetar sentido e valor onde já nada reina para além de um deserto apático.

Em verdade, como apontou Leher no GT Clacso, 'Universidad y Sociedad', alguns intelectuais, talvez os últimos sacerdotes nitscheanos, terminaram por reforçar os processos de globalização hegemônica. De acordo com o texto base do GT de 2006, a questão transcende uma análise simples, uma culpa do Estado e seu governo, da regulação ou desregulação dos mercados, porque ela compreende a formação de um pensamento hegemônico, de uma ação de intelectuais que passaram a assumir a função de porta vozes de governos eleitos nos países periféricos, a liderar as reformas. Muitos dentre eles, denominados 'intelectuais coletivos do capital', inseriram em suas práticas os princípios e pressupostos 'bancomundialistas'. Ou seja, como disse Leher no texto da Propuesta do GT:

Muitos intelectuais ocuparam cargos nesses governos para implementar "reformas" baseadas no pressuposto de que o problema das universidades era o excesso de Estado: abri-las para a sociedade (leia-se, para o mercado) poderia assegurar novos ventos que removessem o bolor europeu. E essa inteligência ganhou força e prestígio junto aos financiadores privados e à burocracia governamental e, por isso, passaram a ser atores ainda mais importantes dentro e fora da universidade (LEHER, 2007, s/p). 
$\mathrm{Na}$ intencionalidade de resistir à cultura da indiferença em relação aos processos de dominação, de encolhimento do espaço público, suas instituições e tecnocracias a serviço do mundo dos negócios, sinaliza-se a importância de compreender o novo imperialismo. Bobbio (1986) apresenta as fases que constituíram o processo de desenvolvimento do imperialismo, possibilitando compreender sua historicidade no contexto do desenvolvimento capitalista. Apenas para lembrar, na primeira fase do imperialismo, entre 1870 e a Primeira Guerra Mundial, efetivou-se a repartição da África entre os Estados europeus e a ocupação de vastos territórios da Ásia com a participação de Japão e Estados Unidos da América (EUA). No período da Primeira Guerra se explicitou a natureza agressiva da expansão imperial, sua conexão com o desenvolvimento do capitalismo, num contexto de concorrência entre as economias fortes. "Intimamente relacionado com o projeto econômico de expansão imperial, os Estados tiveram um papel central, girando suas armas e não poupando despesas para defender os seus interesses econômicos nacionais no exterior" (HARTMANN, 2008). Hartmann aponta uma primeira onda, denominada fase por Bobbio, que caracterizou o conteúdo destrutivo do imperialismo capitalista. Entre 1914 e 1945, propagou-se um imperialismo agressivo, com conteúdo nazifascista, através da política de domínio por parte da Alemanha, Japão e Itália. Estes países visavam a estender sua hegemonia sobre grande parte do mundo. Após 1945, atenuou-se o impulso imperialista dos Estados europeus e do Japão, incidindo um processo de descolonização de diversos países.

No contexto pós-guerra, visualizou-se a continuidade de diferentes formas de imperialismo, através das políticas neocolonialistas das duas superpotências - EUA e União das Repúblicas Socialistas Soviéticas (URSS). Junto com esses movimentos, Bobbio (1986) ressalta a formação de uma postura crítica, em grande parte do mundo, sustentada na análise de que o imperialismo está em contradição com o princípio de autodeterminação dos povos, presente no ideário da Revolução Francesa e na Declaração de Direitos Universais da Organização das Nações Unidas (ONU). Na segunda onda, também apontada por Hartmann (2008), a reconstrução da Europa na agenda internacional tomou forma de uma estratégia imperialista articulada com a formação do capitalismo fordista, incluindo a mercantilização das relações sociais. As críticas a esse processo pautaram a discrepância entre a disseminação global do sonho fordista e a capacidade de efetivá-lo.

A terceira onda do imperialismo, segundo Hartmann (2008), difere das formas anteriores do imperialismo. Seria um imperialismo sutil que a autora denomina de versão benevolente. Sua liderança reside na Comunidade Europeia 
(CE), em seu setor educativo. Constitui-se principalmente através do Processo de Bolonha. Essa forma de imperialismo fortalece as articulações de determinados poderes centrados nos Estados europeus, materializados na Comunidade Europeia como um ator global. A intencional implementação de uma política internacional de educação, de um padrão europeu, visando atingir o mundo na totalidade, inclui a AL e Caribe; expressa o exercício do poder europeu numa busca para atingir interesses capitalistas através de corações e mentes.

Segundo Hartmann, o imperialismo benevolente faz parte das políticas educacionais da Comunidade Europeia através do Processo de Bolonha. Esse processo sutil, além de buscar um mercado para exportação de 'serviços' (como Educação Superior), pretende exercer sua força intelectual disseminando valores e conhecimentos através da sua normatividade intencional para direcionar as políticas educacionais.

O imperialismo benevolente irradia seu processo de dominação e exploração através de uma perspectiva que torna possível ampliar a forma de dominação com um mínimo de coerção. A hegemonia nessa forma de imperialismo se faz pela promoção de um modo de vida, formas de pensar, agir e consumir nos moldes da lógica do mercado europeu. A educação, nesse sentido, tem papel fundamental na socialização de normas e princípios compatíveis com esse mundo existente.

A universidade e os intelectuais seriam atores importantes dessa ordem. Seu papel se desdobra na organização da sociedade do conhecimento, na sustentação da constelação de poder formada por Europa do Conhecimento, Processo de Bolonha e internacionalização da Educação Superior. A homogeneidade dos currículos, avaliação e acreditação, padronização e veiculação de valores mercantis seriam as políticas desejadas para a América Latina, as quais orientam e financiam projetos de cooperação e estabelecem padrões de qualidade para aferir a Educação Superior.

À primeira vista, a difusão global de normas desenvolvidas no processo de Bolonha parece apoiar a ideia de que a União Europeia (UE) surge como uma potência emergente. Estes padrões tornaram-se um ponto de referência na América Latina, África e Ásia, desafiando a prevalência dos padrões dos EUA (HARTMANN, 2008, p. 5).

A Educação Superior teria um papel estratégico na efetivação deste imperialismo europeu sutil. A dimensão ideacional do Processo de Bolonha poderia estar a infiltrar, dentro do possível, processos de coerção na constituição de agendas políticas. A nova dinâmica estaria baseada na persuasão e na sedução 
dos sujeitos sujeitados, atuantes em diferentes instituições de Educação Superior (IES). Influiria, inclusive, nas políticas de Estado.

Há consequências das políticas características da terceira onda do imperialismo, no que diz respeito à desconsideração do local, da diversidade cultural, da história, da formação do sujeito político, do levar em conta o cotidiano vivido pelos diferentes sujeitos inseridos nas instituições universitárias, nas organizações e nos movimentos sociais. A desconstituição da condição de sujeitos políticos, capazes de argumentar, pensar e construir possibilidades de qualidade educativa para a realidade latino-americana está presente nessa dinâmica global. Isto não significa entender essas políticas como um arbitrário cultural ou dar lugar à arbitrariedade do desejo de uma política de isolamento. $\mathrm{O}$ direito à diferença, à interlocução com a diferença, à escuta e à construção coletiva são singularidades que não podem ser negligenciadas no contexto das políticas empreendidas pelos países centrais com vistas aos países periféricos. Uma questão é a exportação de políticas; outra, a dominação através das políticas.

A seguir, evidenciam-se sinais e práticas do novo imperialismo.

\section{SINAIS DO NOVO IMPERIALISMO NA EDUCAÇÃO SUPERIOR: OS ACONTECERES NA PRÁTICA}

Existem possibilidades e alternativas para a Educação Superior. Os aconteceres na prática, decisões tomadas, podem ser visualizados nos projetos, nas ações e nos movimentos políticos amplos que configuram a existência de um novo centro hegemônico do capitalismo interessado na Educação Superior da América Latina porque esta vive a sua 'década brilhante'2.

Os binóculos ou sextantes da Europa do Conhecimento, um dos centros hegemônicos em questão, estariam focados na avaliação e acreditação das instituições, na internacionalização da Educação Superior e na imposição das estratégias do Processo de Bolonha com vistas à formação de uma Uealc ou Alcue, uma zona comum de Educação Superior formada por América Latina, Caribe e União Europeia. Há atores hegemônicos que sustentam esses interesses.

A instituição do novo imperialismo está a se fazer pelo setor de serviços, nomeadamente informática, finanças, serviços jurídicos, de seguros, de saúde e

2 Expressão de manchete do jornal Brasil Econômico. Disponível em: <http://www.brasileconomico.com.

br $>$. Acesso em: 30 de maio de 2011. em referência e oposição à 'década perdida' de 1980. A ‘década brilhante' faz referência ao crescimento da economia, em torno de 6\% no ano de 2010 e 4,75\% em 2011 levando o BID a falar em "decênio da AL" e o The Economist a se apropriar da ideia. 
educacionais. No que se refere à Educação Superior, têm destaque os padrões derivados do Processo de Bolonha, a referência de qualidade para o mundo, não apenas para a Europa. Tais padrões foram entendidos pelo conselho da UE em 2002 como "a world quality reference by 2010" (HARTMANN, 2008). Em relação à introdução das competências nos currículos, faz-se ouvir uma crítica forte por parte dos intelectuais de vários países latino-americanos. Há crítica também dos europeus sobre a Europa das Competências (ANGULO RASCO, 2008; ABOITES, 2010).

Na prática, estão em jogo os valores e a moral hegemônica que se expande sobre e com as instituições de Educação Superior. O primeiro sinal de sua presença é a construção do espaço comum de Educação Superior. Este se está a edificar 'a la Bolonhesa' com o Tuning América Latina ${ }^{3}$. Estuda-se como tornar os currículos latino-americanos assemelhados aos europeus - de modo a favorecer, teoricamente, o intercâmbio e a mobilidade discente - a partir da introdução das competências curriculares em carreiras de formação profissional universitária. As competências curriculares facilitariam a medida dos padrões de qualidade da formação oferecida nas IES. Tal medida de qualidade, além das competências homogeneizadoras, se sustentaria sobre indicadores de qualidade.

Ao padrão europeu, buscam-se sócios para projetos que objetivem uniformizar indicadores. Os padrões seriam sugeridos pelos estudos de Infoaces ${ }^{4}$, o qual se associa ao Mapa da Educação Superior na América Latina e no Caribe (Mesalc), programa do Instituto Internacional para a Educação Superior na América Latina e no Caribe da Organização das Nações Unidas para a Educação, a Ciência e a Cultura (Iesalc/Unesco) para 'mapear a realidade das IES latino-americanas. O Projeto Infoaces declara formalmente que há uma desestruturação do sistema de ES da AL. Tal desestruturação possui peculiaridades, entre as quais, uma dupla função das IES privadas que teriam ensino de menor qualidade, mas atenderiam à massa desprivilegiada socialmente da população estudantil.

3 O Projeto Tuning AL, de acordo com o Informe Final de 2007 (BENEITONE et al, 2007), teria sido proposto por acadêmicos latino-americanos com o propósito de promover sinergias entre o referencial teórico-conceitual dos cursos de graduação europeus e latino-americanos de ES.

4 O projeto Infoaces (2011), Sistema Integral de Informação sobre as Instituições de Educação Superior de América Latina, objetiva criar um sistema integral de informações sobre as IES de AL que venha a servir de suporte para a ACES, Área Comum de Educação Superior em sinergia com a UE, União Europeia (INFOACES, Projeto, Parte B. Objetivos, 2011, p. 22). 


\section{ATORES E AGÊNCIAS GLOBAIS NA EDUCAÇÃO SUPERIOR DE AL: CRÍTICAS}

São várias as agências internacionais globais que operam na América Latina. Dentre as agências globais, destaca-se o papel e a ação da UE e a formação da área comum de Educação Superior, Alcue ou Uealc. Dentre as demais agências globais salienta-se a presença da Unesco, e do Iesalc/Unesco, e do Banco Mundial (BM) em projetos de Educação Superior na AL.

Dentre as agências nomeadas, figura um órgão, uma iniciativa do Banco Mundial, Gicaq, a Iniciativa Global para financiar as práticas de asseguramento da qualidade (QA) das IES. Fazem parte do seu Governing Board a Unesco e o INQAAHE, a International Network for Quality Assurance Agencies. Segundo o Banco Mundial (UNESCO/WORLD BANK, 2008), a Unesco, por sua Divisão de ES, é a única organização das Nações Unidas com mandato explícito para conectar ministérios, agências internacionais e realizar parcerias em 194 diferentes países do mundo. O Banco Mundial declara que considera a Unesco a única agência da ONU que possui mandato em Educação Superior, de tal forma que, ao fazer parte do conselho diretor do Gicaq, a Unesco também toma parte nas decisões sobre o financiamento das iniciativas relativas ao asseguramento de qualidade. A Gicaq apoia as práticas de QA de IES de Europa, Ásia, América Latina, África e países Árabes.

A iniciativa do Gicaq $^{5}$ visa à harmonização de credenciais e competências em práticas de QA. Sua missão é dar suporte e assistência técnica a governos, agências e universidades para desenvolver sistemas de QA e, especialmente, sistemas de mútuo reconhecimento. Seus esforços se direcionam também para treinamento de pessoal, desde profissionais a docentes e acadêmicos e técnicos de governos, em QA. Pode contribuir também para a análise e relatoria de sistemas de QA.

A julgar pelas informações, os atores globais que têm presença em Educação Superior, em processos de avaliação, asseguramento da qualidade, acreditação das IES e dos SES, acreditação de agências acreditadoras, mantêm conexões entre si. As interligações aparecem sutilmente quando se passa a manejar as informações e a examinar os vínculos que ligam os atores entre si. Esses vínculos são observáveis nos sites das agências, nos folders, nas proposals, nos programas conjuntos, nos relatórios, nos apoios oferecidos pelas associa-

5 Gicaq. Disponível em: < http://web.worldbank.org/WBSITE/EXTERNAL/TOPICS/EXTEDUCATI ON/0,,contentMDK:21723791 isCURL:Y menuPK:617592 pagePK:148956 piPK:216618 theSite PK:282386,00.html>. Acesso em: 16 jun. 2011. 
ções de universidades, associações de reitores, redes de avaliadores, redes de acreditadoras.

A ação da Unesco em relação à difusão de Bolonha vem sendo questionada. Hartmann (2008, p. 213), ao revisar o tema, mostra que o mútuo reconhecimento das qualificações da Educação Superior foi estabelecido pela "Convenção para Reconhecimento das qualificações da Educação Superior na região europeia" assinado em abril de 1997, após a Convenção de Lisboa. A Convenção de Lisboa foi ratificada em um tratado conjunto firmado entre Unesco e Conselho da Europa. Os Estados signatários são os países membros da Unesco e da UE. Hartmann observa que a escolha da Unesco para acompanhar o acordo extrapolou os territórios europeus e introduziu uma dimensão 'transatlântica' no regime de mútuo reconhecimento europeu porque esta Convenção também foi assinada por EUA, Canadá e Austrália. Em suas palavras textuais, este fato foi visto como uma surpresa!

Ao buscar entender o fato surpresa, Hartmann se refere ao legado da Guerra Fria, ainda remanescente. Explica que os EUA foram incluídos desde o princípio na Convenção de Lisboa, o que também seria estranho, porquanto, à época, esse país não era membro da Unesco (motivo: o descontentamento do Presidente Reagan em termos da política internacional da mesma). Hartmann cita as palavras de um expert do Processo de Bolonha que manifesta explicitamente: "Com a Convenção de Lisboa você teria a área Europeia-Norte-americana de Educação Superior, porque ambos EUA e Canadá são parceiros potenciais da Convenção de Lisboa". Então, o que é visto por muitos, o Processo de Bolonha como uma resposta competitiva de Europa frente aos EUA, cai por terra. $\mathrm{Ou}$ seja, a Europa do Conhecimento, ou das Competências, não compete com os EUA em termos de Educação Superior. Ela é uma alternativa também para a ES norte-americana. É uma aposta alternativa para o mundo.

No espaço global, contraditório e ambivalente, EUA e Europa são, ao mesmo tempo, rivais e modelos um para o outro. Os padrões e normas norteamericanas estão coexistindo em simbiose com os padrões e normas europeus, de modo que há mútua aceitação de padrões de Garantia ou Asseguramento de Qualidade (QA), realizada por instituições intermediárias. Tais padrões mostrariam essa ambivalência ou cedência de poderes imperiais. Ora, a QA é um mecanismo top do Processo de Bolonha com vistas ao reconhecimento de cursos entre diferentes instituições de diferentes países. Literalmente, diz Hartmann (2008, p. 214), a norma americana de acreditação desenvolvida em processo de livre-mercado também serviria aos estados membros da UE e ao mundo: 
The establishment of a quality assurance (QA) agency, however would facilitate not only the recognition of qualifications but also the Europeanization of the evaluation through intermediary organisations.

Haveria, pois, a partir de Bolonha, um mercado global de agências de acreditação dominado por países onde as agências estão bem estabelecidas, tal como nos EUA e, a partir de Bolonha, também na Europa. Claro está, para a autora, que o simples pensar nesta hipótese levou a Comissão Europeia a estabelecer que somente poderão vir a ser agências de acreditação aquelas agências que se ajustarem à norma europeia, determinada pelos padrões de qualidade do European Register of Quality Assurance Agencies.

Cabe registrar que, para os demais países, inclusive para a América Latina, os padrões europeus de qualidade tornaram-se "os padrões de boa qualidade"; que as agências de acreditação, ou QA não europeias, deverão adotar e seguir as normas europeias. Os padrões da "boa qualidade" se tornam, então, uma necessidade para todos os sistemas de ES do mundo global. Esses padrões contam com a chancela da Unesco, uma instituição de alta credibilidade por suas iniciativas em relação à Educação Superior!

Apresentadas brevemente as agências e as críticas, veja-se que a entrada do novo imperialismo na AL guarda forte conexão com processos de avaliação e acreditação.

\section{AVALIAÇÃO E ACREDITAÇÃO DA ES EM AL E CARIBE: A PORTA DE ENTRADA DO NOVO IMPERIALISMO}

As redes de agências de acreditação e avaliação da qualidade da Educação Superior na América Latina se estabeleceram nas últimas décadas. Muitas dentre as agências nacionais produzem apenas autorização e reconhecimento de cursos e instituições, outras realmente atuam em Acreditação e Avaliação periódica de instituições e programas. Na definição clássica de acreditação, como explica Dias Sobrinho, acreditar se define como comprovar a qualidade das IES. Acreditar corresponde a dar fé pública de qualidade às instituições ou aos programas de estudos; é expor informações aos cidadãos e às autoridades garantindo publicamente que os títulos outorgados apresentam os níveis predefinidos; é comprovar oficialmente que uma instituição educativa - ou um programa específico - cumpre ou não com os requisitos de qualidade (DIAS SOBRINHO, 2007, p. 282), com apoio em GUNI.

À parte de comprovar a qualidade das IES, os processos de acreditação estão a cada momento se transformando em poderosos definidores das instituições 
de Educação Superior e de seus currículos de graduação e do perfil que deve ter um docente ou um pesquisador. Para além da 'simples' qualidade, há um componente político de extraordinária importância.

O componente político guarda relação com os atores globais. Pesquisa recente de Guerra (2010) coletou entrevistas de líderes de avaliação latinoamericanos. Um dos entrevistados faz parte de Coneau, Argentina. Ao confirmar as conexões entre os atores globais, disse ele que "os processos de Acreditação e Avaliação da qualidade da Educação Superior na América Latina se tornam instrumentos políticos de negociação com organismos, por exemplo, o Banco Mundial. Pressupõem que países que adotam esses processos de legitimação da qualidade da Educação tenham mais condições de comprovar credibilidade para o recebimento de investimentos nas negociações com o Banco." Ou seja, buscar qualidade legitima uma IES frente ao Banco, legitima um sistema de Educação Superior no plano da globalização.

A reunião de agências de acreditação em redes é um fenômeno relativamente recente na América Latina e Caribe. Além da Rana, rede estabelecida no âmbito do Mercosul, outras redes de agências de acreditação estão em atuação no continente latino-americano e Caribe, dentre elas a Rede Ibero-americana para Acreditação da Qualidade da Educação Superior (Riaces), cuja força neste momento reside em seus apoios europeus dados por Gicaq-Unesco/BM, INQAAHE, Holanda e Aneca, a Agencia Nacional de Evaluación de la Calidad y Acreditación da Espanha. A Riaces, que está se projetando no cenário por seus vínculos com importantes atores globais, congrega várias agências locaisnacionais e associações de reitores, de universidades e outras.

A Rana, Rede de Agências Nacionais de Acreditação e o Arcu-Sur, Sistema Regional de Acreditação de Cursos de Graduação são redes que se estabeleceram sob os auspícios do Mercosul Educacional com a finalidade de reconhecer os diplomas de nível superior de carreiras profissionais de Medicina, Engenharia, Agronomia, Arquitetura, Enfermagem, Medicina Veterinária, Odontologia no âmbito dos países integrantes do tratado do Mercosul, de modo que, após os procedimentos de avaliação acreditadora, a formação recebida pelos egressos dessas carreiras profissionais possa ser aceita em diferentes países. A Rana congrega as ANAs, agências nacionais de acreditação dos diferentes países, representantes dos Estados-membros e associados do Mercosul (Ver quadro 1).

A Riaces, Rede Iberoamericana para Acreditação da Qualidade da Educação Superior, surgiu em 2003, em Buenos Aires, Argentina, com sede junto à Coneau. Sua finalidade é reunir agências de avaliação e acreditação e outros organismos de mesma finalidade. A Riaces, segundo consta em sua página 
web $^{6}$, mantém "un estrecho relacionamiento con Gicaq desde que esta iniciativa se ha puesto en marcha. En el marco de esta cooperación Riaces ha podido desarrollar una serie de acciones que han repercutido muy favorablemente en el desarrollo de la Red". Entre as ações desenvolvidas com o apoio do Gicaq (BM), encontram-se a realização de reuniões técnicas do Projeto CINTAS (uma iniciativa de asseguramento da qualidade, cujo nome provem de Calidad Interna de las Agencias de Evaluación y Acreditación), apoio à autoavaliação de agências da rede, visitas, programas de treinamento e intercâmbio, apoio a programas de acreditação de cursos de graduação em Engenharia, apoio à comunicação entre as agências e difusão de informações.

A Riaces mantém uma página web também financiada pela Gicaq, programa conjunto do Banco Mundial e Unesco. Nessa página informa que decidiu desenvolver um "componente clearinghouse em sua página web para concentrar informações sobre as agências que compõem a Rede". O projeto está implementado com o objetivo de "Desarrollar en la Web, un componente de Clearinghouse sobre los documentos oficiales y los instrumentos de evaluación y acreditación de las agencias miembros que contribuya con el desarrollo y la administración del Clearinghouse de INQAAHE”. A Riaces mantém vínculo com a INQAAHE e com a Aneca da Espanha e acordos e convênios com a maior parte das agências acreditadoras de AL (Ver Quadro 2).

Ao considerar, além da ação das grandes agências internacionais globais e das redes de acreditadoras, a indução produzida pelos rankings internacionais, tem-se um quadro novo que sugere um imperialismo benevolente a difundir hegemonicamente valores e concepções europeias. O tema dos rankings, ao contrário do tema das avaliações e acreditação, tem sido ignorado pelos acadêmicos. Porém, resulta que sua aceitação não se faz sem críticas. No entanto, eles são lidos e referenciados como pauta de marketing das instituições que alcançam posição entre as dez primeiras, as 100 melhores IES, as 500 IES de qualidade e assim por diante. Na base dos sistemas de indicadores estão critérios decididos pela sociedade dos amigos. Critérios que se baseiam na possibilidade de obtenção de dados de diferentes IES a partir de fontes tradicionais e, em geral, aceitas pelos investigadores.

Como sobejamente reconhecido, os rankings têm a ver com a medida das pesquisas e da produção de conhecimento, têm a ver com instituições internacionalizadas, com modelos e tipologias de instituições ditas de qualidade, com indicadores internacionais de avaliação que foram decididos longe da $\mathrm{AL}$, com

6 Conforme a página da Riaces. Disponível em: <http://www.riaces.net/index.php/es/acerca-de-riacesique-es-riaces.html>. Acesso em: 28 jun. 2011. 
processos de globalização e internacionalização das IES. Os rankings estão a sofrer auditorias, o que comprova que ganham força no cenário global como novos e grandes atores.

Os rankings perderam a inocência, eles tratam de uma mercadoria chamada conhecimento, da economia do conhecimento, de sua produção e disseminação. Faz-se necessário destacar que não estão a atingir apenas as IES. Os rankings medem o conhecimento que um país produz. Ou seja, o quanto de valor financeiro o conhecimento, a inovação e as tecnologias da informação agregam (WORLD BANK, 2009).

\section{AMÉRICA LATINA, PARA ONDE VAIS?}

Frente ao exposto, conclui-se que as políticas de avaliação e acreditação dos distintos países estão afetadas pela agenda internacional. Esta agenda carrega consigo uma forma de atração e sedução próxima ao soft power, a habilidade para conseguir o que se deseja conseguir mais pela atração do que pela coerção ou pelo pagamento, como define Nye (2004). Este soft power não parece arrogante. Pelo contrário, ele se faz legitimar pelo concurso dos próprios acadêmicos e suas instituições e, por isso, é bem aceito. Há um soft power de formato pós-moderno que incrementa as estratégias de mercadorização da Educação Superior. Contudo, mesmo que se possa considerar a atratividade dos processos de asseguramento da qualidade, dos rankings e do desejo de melhoria e de alcance da melhor qualidade internacional para todas as universidades da América Latina e do Caribe, não se pode desdenhar a perspectiva da existência de um novo imperialismo, o imperialismo benevolente. Torna-se difícil fazerlhe a crítica e traçar as evidências de sua presença.

Onde estariam os principais pontos que traçam as evidências?

O 'novo' imperialismo hegemônico está focado no conhecimento e na informação. Há uma disseminação de suas forças na América Latina. As instituições de ES seriam o objeto visado, pois, nelas se desenvolvem o conhecimento, a investigação e a formação do 'capital humano'. A incidência dessas forças não constitui uma relação de causa e efeito ou de opressão ou de determinações. São movimentos de sedução, de convencimento e proposições lógicas e racionais que se fazem por dentro das múltiplas relações estabelecidas entre instituições, organizações, atores globais e acadêmicos.

As políticas buscam incidir no cotidiano das práticas de forma a serem naturalizadas e internalizadas como necessárias, como a melhor possibilidade, como ideário a ser buscado. A neolíngua que produz um discurso próprio tem 
uma palavra central - qualidade da universidade. Dentro deste vocábulo está inserida a avaliação, a acreditação, o ranking, o indicador de qualidade, a internacionalização das instituições, enfim seu desempenho no mundo global frente a suas congêneres locais e internacionais.

Os valores pelos quais esta lógica passa a operar são sutilmente transplantados do mundo dos negócios para o mundo acadêmico. Eles incluem o risco, a competição, a parcimônia, a lucratividade, o valor do dinheiro, o empreendedorismo, dentre outros, em um circuito descolado das demais relações que compõem o ser humano para além do negócio. $\mathrm{O}$ reflexo desses valores na Educação Superior se faz sentir em todas as esferas de ação educativa das instituições. Curiosamente, estes valores estão sendo tecidos pela Europa do Conhecimento.

Os desdobramentos teriam a ver com o fato de a América Latina ser neste momento o segundo maior parceiro de negócios da Europa. Teriam relação com as línguas aqui faladas, o espanhol e o português, com as ex-colônias, com a formação de uma 'comunidade' ibero-americana ou uma zona Uealc; seriam mais um produto do neocolonialismo e universalismo europeus. Tais desdobramentos certamente são reflexos de um imperialismo benevolente traçado pela sociedade dos amigos. Ainda que sejam relações não lineares, são relações que se percebem como existentes, com tendência ao crescimento nos próximos anos.

É importante considerar que, no nível interno das instituições, esta lógica externa, do mundo dos negócios, incide na formação dos sujeitos de tal modo que a formação social e política repartida pela Educação Superior tradicional vai sendo minada e fragilizada. Nesta condição, o docente e o pesquisador, o estudante e o técnico são instados a adotar os parâmetros da produtividade e da competição para se legitimarem como sujeitos eficazes e eficientes. Estão a aceitar parâmetros curriculares baseados em competências. Talvez em uma atitude de pura 'distração'. Esta seria a face mais danosa da lógica da mercadorização de origem neoliberal, a face disciplinar, que incide sobre o pensar do sujeito, do ser social e político, no interior das instituições. A face em que os preceitos econômicos de mercado são preponderantes sobre os demais.

A infiltração neoliberal já estava dada desde os anos 1970-1990, como os estudiosos das reformas bem a evidenciaram, como vários autores o denunciaram. Neste momento, o que se observa é o reforço do liberalismo quantitativista com o concurso das avaliações e acreditações, apropriadas como um mecanismo imperial pela UE com o suporte e estímulo do soft power de grandes atores globais. Não se trata de um fator isolado. O que se observa no momento é que há uma conjugação de fatores, agentes, forças, valores, mecanismos legais, 
cobertura financeira, na mesma direção, promovendo a mesma ordem de ideias. Particularmente, aponta-se, neste ensaio, a força do Processo de Bolonha, do Projeto Tuning, da regulação das redes de Agências de Avaliação e Acreditação e dos rankings internacionais. Vários programas do tipo Infoaces, Mesalc, e outros, estão a contribuir na mesma direção.

Um novo imperialismo, na sua forma benevolente, está a se constituir tendo a Europa do Conhecimento como centro hegemônico e a América Latina como centro subordinado. O conhecimento uniformizado se estabelece através da avaliação e acreditação. A dominação política se estabelece pelo consentimento e adesão.

Um conjunto de referenciais sustenta a ordem das ideias. Em resumo e reforçando, os referenciais dizem respeito à Qualidade, com Q maiúsculo, dos sistemas de Educação Superior, à internacionalização das instituições, à avaliação e acreditação das instituições, aos indicadores e padrões de desempenho suportados por agências internacionais de acreditação que se regulam pela norma europeia, a qual está em consonância com as normas norte-americanas. Dentre esses referenciais, vale citar aqueles que o Banco Mundial apresenta, como, por exemplo, o Education for the Knowledge Economy (WORLD BANK, 2009). Uma referência politica para os países em desenvolvimento. Visa criar uma base de capital humano, uma força de trabalho educada que compartilharia habilidades de alto nível dispensadas por instituições acreditadas segundo as normas. Seria preocupação de cada país oferecer diplomas certificados por instituições acreditadoras ${ }^{7}$ de forma a poder competir nos mercados globais. A sociedade dos amigos enfatiza a necessidade da homogeneização dos indicadores, chamados indicadores de qualidade, para definir e tipificar as melhores instituições. Não se trata de homogeneizar para destacar ou igualar, mas, para subsumir, aumentar a exclusão.

Enquanto o imperialismo benevolente pode ser facilmente identificado nos movimentos mais amplos dos atores globais, o movimento subjetivo das relações entre os sujeitos, nos diferentes contextos, torna-se difícil de visualizar. Afinal, trata-se de melhorar a Educação Superior na América Latina e no Caribe, que está denunciada como diversa e desestruturada. O Projeto Infoaces, por exemplo, faz um arrazoado sobre a necessidade de indicadores para homogeneizar as 'desestruturadas' IES latino-americanas. Para melhorar toda a Educação Superior na AL e no Caribe, reúnem-se acadêmicos em eventos internacionais

7 "[...] to cultivate the highly skilled, flexible human capital needed to compete in global markets - an endeavor that affects a country's entire education system." "And they must offer recognized certificates through internally accredited institutions" (WORLD BANK, 2009). 
do maior respeito; trata-se de financiar os eventos, a acreditação e a mobilidade estudantil, docente e de pesquisadores para melhorar a formação e a pesquisa na ES; trata-se de melhorar a informação entre as IES. Cita-se o exemplo do clearinghouse de Riaces onde os documentos das IES serão visíveis e a relação com a INQAAHE, a Aneca, o Gicaq e a Unesco está naturalizada; trata-se de melhorar a performance individual dos acadêmicos em termos de capacidade de produzir publicações nacionais e internacionais, em inglês. Trata-se de planejar atentamente, estudar, difundir e implementar políticas de qualidade, entre amigos. Afinal, está-se a concretizar 'boas práticas' de relações internacionais entre neocolonizadores e neocolonizados!

Por adiante e por detrás dos procederes, segue a uniformização dos currículos, a marca das competências e habilidades padrão em carreiras profissionais, o redesenho das instituições, a uniformização de indicadores de avaliação homogeneizadores da Educação Superior, se possível com submissão aos 'Register' europeus, a tipologização das IES no parâmetro internacional e a constituição de redes que subsomem os sujeitos individuais e suas capacidades protagônicas. Nesta condição, os sujeitos individuais são considerados uma peça das redes que são dirigidas pela sociedade dos amigos com mandato de conselhos consultivos, conselhos deliberativos e outros. Qual é a origem da representação da sociedade dos amigos? Quem decidiu? Quem participou das decisões? Com que propostas se elege e atua a sociedade dos amigos? De agora em diante as instituições de Educação Superior deverão submeter-se e pagar as acreditações e avaliações propostas pela sociedade dos amigos? Elas já constituem um mercado cativo da sociedade dos amigos?

Surpreende ver a facilidade e a rapidez com que tais fatos e acontecimentos estão ocorrendo à revelia da grande maioria dos acadêmicos. Os acadêmicos estão afetados no fazer cotidiano pelas exigências das normas avaliativas baseadas nos princípios da produtividade capitalista. Fragilizados em sua condição de ser político, os acadêmicos e seus estudantes se indagam sobre o valor de sua autoria, autonomia e liberdade acadêmica, princípios tão caros ao fazer universitário. Indagam a si próprios sobre o futuro de suas instituições, transformadas em apêndices de processos gerados em outras realidades. Indagam sobre a ausência de reconhecimento da diversidade e da pluralidade, decorrentes da riqueza cultural e social dos povos latino-americanos. Essa riqueza da condição humana que, nesta parte do mundo, inclui a aceitação étnica de povos que foram transplantados. Povos que se mesclaram e mostram seu caráter inovador e lutador. Tais características do local em oposição ao global ficam desperdiçadas e despedaçadas nos novos modelos de instituição trazidos pelas 
avaliações, acreditação e rankings internacionais forjadas no viés do imperialismo benevolente.

A sociedade dos amigos privilegia a homogeneidade dos padrões e dos indicadores de qualidade. Privilegia o governo de poucos sobre muitos. Destitui o sujeito político e participativo!

A mercadorização da Educação Superior impulsiona a formação do intelectual do negócio, o intelectual capitalista, o sujeito articulado e conectado ao mundo global. Os pressupostos do imperialismo de terceira onda, benevolente, estão a trilhar os caminhos dos currículos e das avaliações com seus valores associados. Como parte integrante e propulsora dos ideais, valores e moral do capitalismo hegemônico, estariam a influenciar a formação do sujeito político. Nessa perspectiva, o outro é um competidor, talvez um inimigo. O sujeito é um consumidor atento à nova ordem para a conformação e conservação de um mundo de benesses e privilégios. Para a formação deste sujeito capitalista contribuiriam os processos e dinâmicas de políticas de avaliação propulsoras de valores tais como individualismo, competitividade e possessividade.

Acredita-se que os processos não ocorrem de forma isolada ou determinística. Eles são mutuamente inclusivos. Não haveria mercadorização sem a ação e o concurso dos sujeitos individuais tanto quanto dos sujeitos coletivos que se produzem e reproduzem no seio das agências globais do capitalismo. Há vantagens imensuráveis no viver, no usufruir em comum uma felicidade parodoxal, para usar a expressão de Lipowetski, que, sem dúvida, são desejáveis por todos. Porém, sensivelmente se observa uma perda da autonomia dos sujeitos frente a palavra de ordem Qualidade!

Se as IES de AL e Caribe estão a enveredar por essas trilhas sedutoras, aonde aportarão no futuro?

Quo vadis América Latina?

\section{REFERÊNCIAS}

ABOITES, Hugo. La educación superior en América Latina y el proceso de Bolonia: de la comercialización al proyecto Tunning de competencias. Educación Superior y Sociedad, Caracas, v. 15, n. 1, p. 25-44, 2010.

ANGULO RASCO, J. Félix. La voluntad de distracción: las competencias en la universidad. In: GIMENO SACRISTÁN, José (Comp.) Educar por competencias? Que hay de nuevo? 2. ed. Madrid: Morata, 2008. p. 176205. 
BENEITONE, Pablo et al. Reflexões e perspectivas do ensino superior na AL. Relatório final: Projeto Tuning-América Latina, 2004-2007. Bilbao: Universidade de Deusto, 2007.

BOBBIO, Norberto. Dicionário de política. Tradução de João Ferreira e outros. Brasília: Ed. UnB, 1986.

BOTTOMORE, Tom (Ed.). Dicionário do pensamento marxista. Rio de Janeiro: Zahar, 1988.

COUTINHO, Luciano. A fragilidade do Brasil em face da globalização. In: BAUMANN, Renato (Org.). O Brasil e a economia global. Rio de Janeiro: Campus, 1996. p. 219-237.

DE ALBA, Alicia. Construción del curriculum y estado evaluador. Pensamiento Universitario, Buenos Aires, v. 2, n. 2, p. 18-28, 1994. DIAS SOBRINHO, José. La acreditación de la educación superior en América Latina y Caribe. In: GLOBAL UNIVERSITY NETWORK. La educación superior en el mundo. 2007: acreditación para la garantía de la calidad? Que está en juego? Barcelona: GUNI; Mundi-Prensa, 2007, p. 282294.

GUERRA, Margareth. As redes de avaliação da qualidade e acreditação da educação superior na América Latina: RANA e RIACES. Porto Alegre: PPGeDu/uFrGs, 2010.

HARTMANN, Eva. Bologna goes global: a new imperialism in the making? Globalisation, Societies and Education, London, v. 6, n. 3, p. 207-220, 2008 .

INFOACES. Sistema integral de información sobre las instituciones de educación superior de América Latina: información básica sobre el proyecto. Reunión general de Infoaces, 16-17 de marzo de 2011. Porto Alegre: UFRGS: Infoaces, 2011.

LEHER, Roberto. (Coord.). Renovación parcial período 2004-2007. Propuesta. Grupo de Trabajo Universidad y Sociedad. Mexico: CLACSO, 2007.

LEITE, Denise Balarine Cavalheiro. Brazilian higher education from a postcolonial perspective. Globalization, Societies and Education, London, v. 8, n. 2, p. 219-233, jun. 2010. 
LEITE, Denise Balarine Cavalheiro; GENRO, Maria Elly Herz. Quo Vadis? Avaliação e internacionalização da Educação Superior na América Latina. Buenos Aires: CLACSO, 2011. Ensaio.

LYPOWETSKI, Gilles. A era do vazio: ensaio sobre o individualismo contemporâneo. Lisboa: Relógio D’Água, 1983.

NYE JUNIOR, Joseph. Soft power: the means to success in world politics. New York: PublicAffairs, 2004.

SANTOS, Boaventura de Sousa. Os processos de globalização. In: SANTOS, Boaventura de Sousa (Org.). Globalização, fatalidade ou utopia? Porto: Afrontamento, 2001.

SANTOS, Boaventura de Sousa; AVRITZER, Leonardo. Para ampliar o cânone democrático. In: SANTOS, Boaventura de Sousa. (Org.).

Democratizar a democracia: os caminhos da democracia participativa. Rio de Janeiro: Civilização Brasileira, 2002.

UNESCO. World Bank. ED/HED/RIQ/2008/PI/24. Global Initiative for Quality Assurance Capacity (GIQAC): governance terms. January, 2008. Paris: UNESCO, 2008.

GIQAC. World Bank. Global initiative for quality assurance capacity. Disponível em: <http://web.worldbank.org/WBSITE/EXTERNAL/TOPICS/ EXTEDUCATION/0,,contentMDK:21723791 isCURL:Y menuPK:61759 2 pagePK:148956 piPK:216618 theSitePK:282386,00.html>. Acesso em: 16 jun. 2011.

INQAAHE. International Network for Quality Assurance Agencies in Higher Education. Disponível em: <http://www.inqaahe.org/main/publications/ quality-networks-214>. Acesso em: 10 jun. 2011.

RIACES 2011 Bienvenido a RIACES: (RedIberoamericana de Asseguramiento de la Calidad de la Educación Superior). Disponível em: $<$ http://www.riaces.net $>$. Acesso em: 06 jun. 2011.

WORLD BANK. Education for the knowledge economy 2009. Disponível em: < http://web.worldbank.org/WBSITE/EXTERNAL/TOPICS/EXTEDUC ATION/0,,contentMDK:20161496 menuPK:540092 pagePK:148956 piPK :216618 theSitePK:282386,00.html>. Acesso em: 28 jun. 2011. 


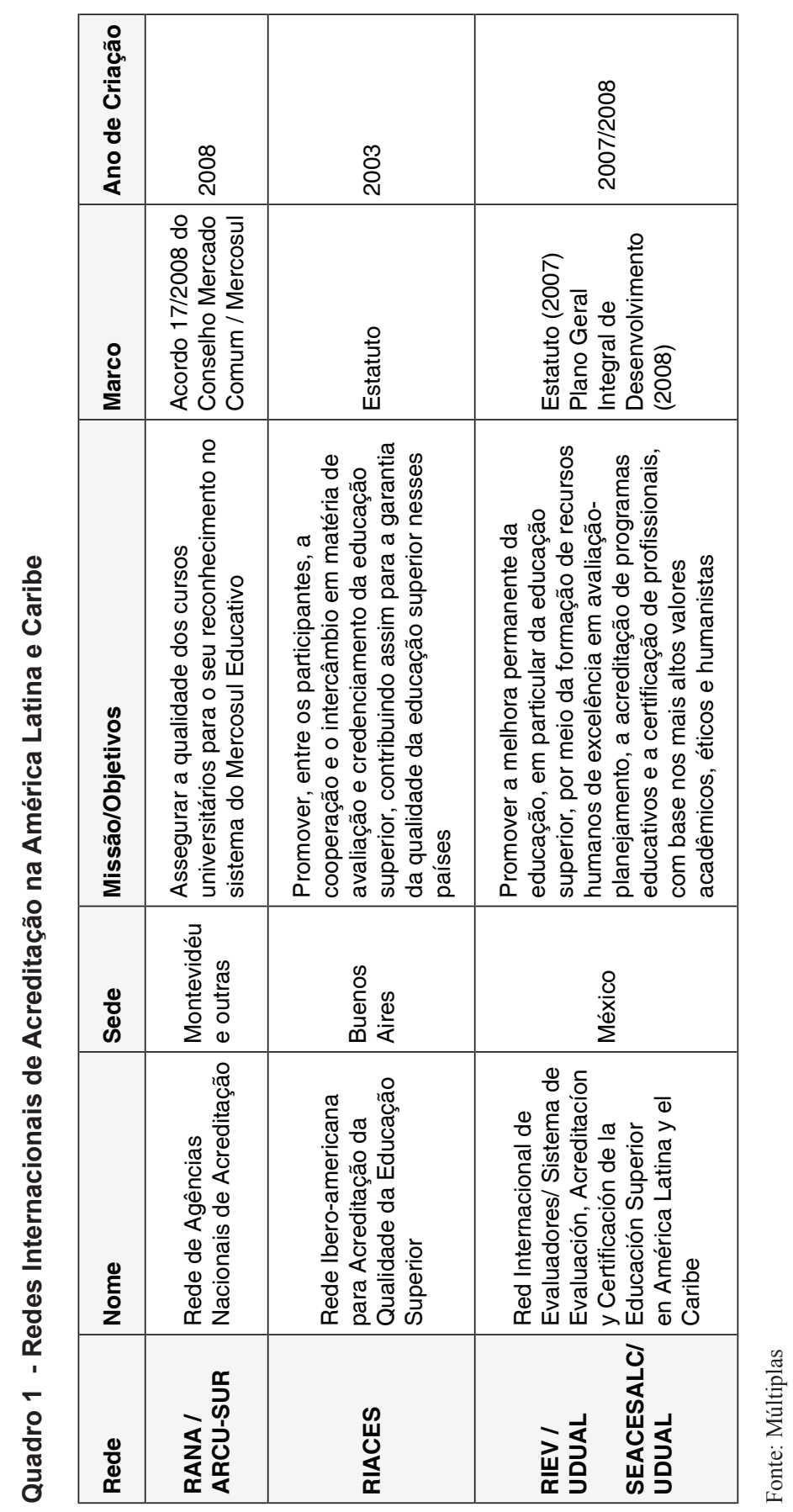

